\title{
Growth of anthraquinone crystals by gel aided solution technique and their characterization
}

\author{
K RAJENDRA BABU, M DEEPA, C M K NAIR ${ }^{\dagger}$ and V K VAIDYAN* \\ Depatment of Physics, University of Kerala, Karievaltom, Thiruvananthaputam 695 581, India \\ Department of Physics, M.G. College, Thiruvananthapuram 695004, India \\ MS received 9 Seplember 1997; revised 28 November 1997
}

\begin{abstract}
Alostract. Anthraquinone, an oxidation product of anthracene, has been grown by gel aided solution technique employing sodium metasilicate. Needle shaped crystals were oblained in $0.5 \%$ (w/v) solution of anthraquinone for pH 5-5. The grown crystals were characterized by optical microscopy, SEM, IR, UV and XRD.
\end{abstract}

Keywords. Gel; solution; anthraquinone; crystal growth; axidation; photoreaction.

\section{Introduction}

Derivalives of anthracene are convertible to other compounds by direct oxidation. Anthraquinone comes under this class of compounds. Considerable work has been reported on the synthesis of anthraciuinone by catalytic oxidation of anthraquinone (1van and William 1949: Owens 1958; Noboru et al 1969; Grozev et al 1976; Chung 1978; Das and Nikhilendui 1982; Maljk and Dohnal 1990; Pielichiouski $e t$ at 1992). The mesopositions in anlaracene acquire the numbers 9 and 10, respectively. The successful outcome of the reaction is due to the special reactivity of the mesopositions and the greater stability of anthraquinone. The double bonds in the central ring ate rendered inert by incorporation of oxygen in the terminal benzene rings (Louis and Mary 1960) Anthraquinone exhibits optical and photosemiconducting properties in addition to third harmonic generation (Yao 1962; Grozev et al 1976; Mizoguchi and Venishi 1991). Anthraquinone crystallizes in the monoclinic system with space group $P_{2} / a \quad(a=1.581, b=0.3942$ and $c=0.7865 \mathrm{~nm})$ with two molectles per unit cell. Here, we report the growth of anthraquinone observed during the growth of anthracene by the gel aided solution technique (Rajendra Babu et al 1998). The grown crystals are characterized by optical microscopy, SEM, IR, UV and XRD.

\section{Experimental}

The chemicals used in this study were of $\mathrm{BDH} / \mathrm{AR}$ grade. Sodium metasilicate of gel density $1.05 \mathrm{~g} \mathrm{~cm}^{-3}$ was prepared, treated with glacial acetic acid in the $\mathrm{pH}$ range $\$-7.5$ and mixed with acetone for different gel

\footnotetext{
*Author for correspondence
}

acelone ratios $(2: 1,3: 1,4: 1)$. The mixture whs allowed to set. The mixtures with higher $\mathrm{pH}(>6.5)$ were set within $48 \mathrm{~h}$, whereas those with lower $\mathrm{pH}$ (5) took nearly one week. Over the set gels, $0.5 \%(w / v)$ solution of anthracene in acetone was incorporated as top solution. The samples were kept open to diffuse sunlight. Few samples were kept in a dark room.

\section{Results and discussion}

It was observed that the level of top solution decreased slightly turing the first week due to slow eveporation and diffusion into the gel. Tiny transparent crystals were observed floating on the surface of the top solution. Within two weeks, yellow needies were found growing from the tiny transparent crystals. Formation of yellow needles of anthraquinone is found to depend on several factors. An imporiant parameter which determined the yield of anthraquinone was the concentration of anthracene solution kept over the gel. Higher concentration (1\%) of anthracene solution produces a large number of anthracene crystals on the gel surface and tiny needies of anthraquinone were formed after a long period ( $\sim$ two months). A better yield of anthraguinone resnlted in a solution of concentration $0.5 \%(\mathrm{w} / \mathrm{v})$ within two weeks.

A typical sample of gel, adjusted for $\mathrm{pH} 5$, over which a few yellow needles of anthraquinone were formed is shown in figure $1 \mathrm{~A}$. In this case, tiny crystals formed on the surface of the top solution moved down to gel surface and yellow needles of anthraquinone grere grown from thetn. In certain other gel samples when the illumination was high, large number of yellow needles were obtained.

Organic crystals can be grown from a wide variety of solverts, but since these solvents are non-aqueous, $\mathrm{pH}$ canuot be used as crystallization variable (Margaret 

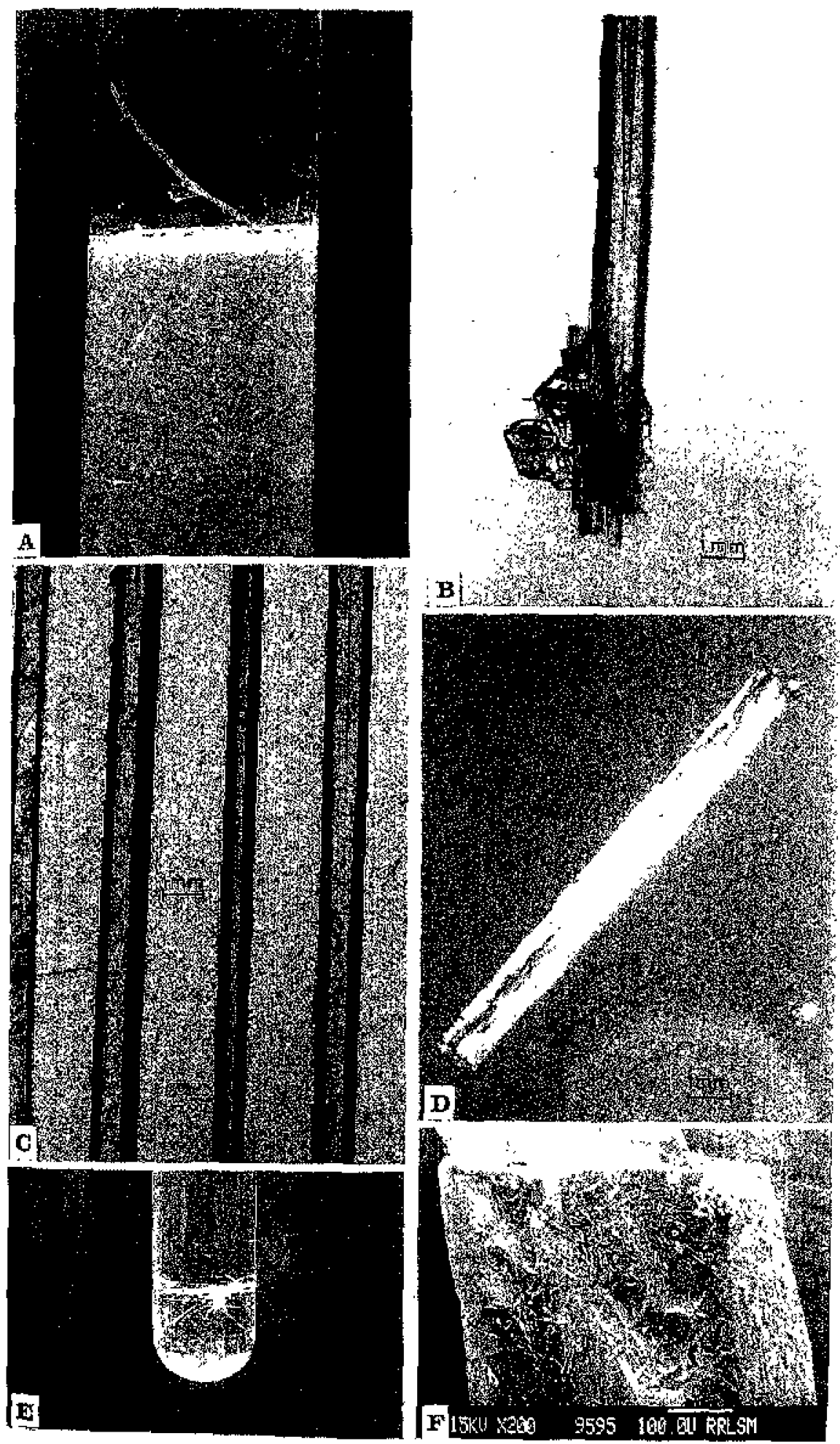

Figure 1. (A) Needles of atritraquinone sen growing in the supernalant solution kept over the gel, ( $\mathbf{P})$ a needle of anthraquinone grown from a cluster of anthracene crystals, (C) micrograph of needles abtained under crossed nicol prism, (D) a single crystal of anthraquilone pholographed in straight extinction position with nicol in $45^{\circ}$, (E) micrograph showing the grow th of a large number of yellow necdles of anthriguinone in acetone-Water solution of anthracene and (F) SEM plolograph of a needle of anthriquinone. 
et al 1986). However, in the present study, crystals were formed only in the top solution of particular $\mathrm{pH}(\sim 6)$, irrespective of the gel $\mathrm{pH}$. Hence, $\mathrm{pH}$ of top solution and in turn pFI of the gel should have some effect on the nucleation of anthragunone. Crystals of anthricjuinone were found to grow in all $\mathrm{pH}$ values tried $(5,5.5,6$, $6.5,7$ and 75). But, better yield was obtained in 5-6 range. Most tavourable $\mathrm{pH}$ was 5.5 in which yellow nedles were found to grow into the gel medium in addition to that in the top solution. The rate of growth of these needles were studied. A uniform increase in the growth tate of needles into the gel medium was observed up to six days, After one week, the crystals attained maximum size, with a lower growh rate. This was followed by dissolution of crystals and the size of crystals fluctuates as shown in fjgure 2.

The samples kept in darkness did not yield yellow crystals of anthracuinone, but mly platy crystals of anthracete. This confiruls that the yellow needles of anthraquinone were produced by the photoreaction of anthracene as reported earlier (Corey and Tirylor 1964).
By the irradiation of anthracene in acetone, anthraguinone is obtained as a final product as represented by the following conversion (figure 3 ).

Investigation on the solvent (acetone) incorporated over the gel in this experiment revealed that there was a gradual increase in the density, surface tension and conductance of the solvent. Hence, it can be presumed that such changes might have modified the anthracene solution favourably for being converted into anthraquinone by photorenction. Density measurement of solvent and solution (table 1 ) showed that the supernatant solution of anthracene undergoes a change similar to the behaviour of acetone-water mixture. Thus the supernatant solution might have been tuned for the growth of yellow needles. The differences in growth of anthracuinone in pure gel and acetone mixed gel is also noted. When the solution was kept over pure gel, the changes in supernatant solution was fast and resulted in the nucleation and growth of large number of anthracenc crystals. Solution over the acetone-mixed gel whs found to undergo a slow change in parameters and lew anthracene crystats were

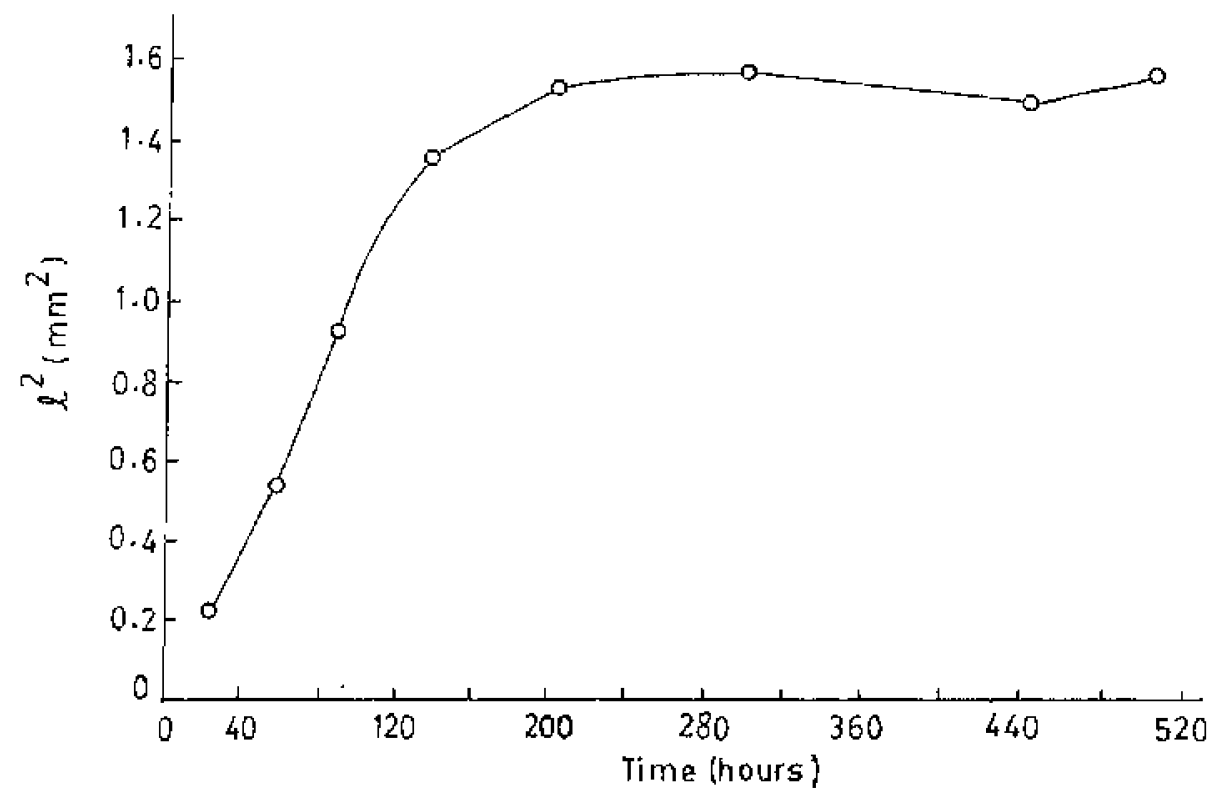

Figure 2. Growh kinetics of anthraquinone crystal.<smiles>c1ccc2cc3ccccc3cc2c1</smiles>

Anthracene

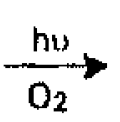<smiles>Oc1ccccc1C1C2C=CC=CC1C2O</smiles>

Anthracene peroxide<smiles>O=C1c2ccccc2C(=O)c2ccccc21</smiles>

Anthraquinone

Figure 3. Photoreaction of anthracene. 
formed. Within this time the solution is tuned for easy photoreaction and growth of atthraquinone.

In order to have better understanding of the role piayed by waler-acetone system, water was mixed with acetone in different proportions. This mixture was used to prepare anthracene solution so as to grow crystals by slow evaporation without the aid of gel. A notable observation was that yellow needles of anthraguinone were formed in acetone-watet system only if a seed was added. Good yield (figure 1E) was obtained when the mixture containing $5-30 \%$ of water was kept in an illuminated room. The crystals were separated, washed, dried and characterized with $\mathrm{X}$-ray powder diffraction, IR, UV-visible spectroscopy, optical and scanning electron microscopy.

Table 1. Density of solvenv/solition at $30^{\circ} \mathrm{C}$.

\begin{tabular}{|c|c|}
\hline SolvenV/solution & $\begin{array}{l}\text { Densily } \\
\left.(\mathrm{g} \mathrm{cJI}]^{-3}\right)\end{array}$ \\
\hline Pure acetone & 0.753 \\
\hline Acetone kept over tho gel for one week & 0.895 \\
\hline Saturated solution ol anthracene in acetone & 0.764 \\
\hline Top solution in which asthraquinonte is lormet & 0.847 \\
\hline
\end{tabular}

Table 2. IR spectral data of anthraquinone.

\begin{tabular}{|c|c|c|}
\hline $\begin{array}{l}\text { Yollow ncedles } \\
\text { grown in acetone } \\
\text { solution kept over } \\
\text { the acetone mixed } \\
\text { gel (cm-') }\end{array}$ & $\begin{array}{l}\text { Yellow needles } \\
\text { grown ij acelone- } \\
\text { water mixture by } \\
\text { solution growly } \\
\left(\mathrm{cm}^{-1}\right)\end{array}$ & Assignment: \\
\hline $\begin{array}{l}937 \\
8[0]\end{array}$ & $\begin{array}{l}935 \\
810\end{array}$ & $\begin{array}{l}\text { Cre out ol plane } \\
\text { bending }\end{array}$ \\
\hline 621 & & Skeletal deform \\
\hline 694 & 690 & Ring broathing \\
\hline $\begin{array}{l}1170 \\
1284\end{array}$ & $\begin{array}{l}1160 \\
1280\end{array}$ & $\mathrm{CH}$ in plarie bending \\
\hline $\begin{array}{l}1304 \\
1332 \\
1473 \\
1522 \\
1635\end{array}$ & $\begin{array}{l}1330 \\
1470 \\
1560 \\
1620\end{array}$ & Ring stretching \\
\hline 1591 & 1580 & $\begin{array}{l}\text { Aromitic vibrations } \\
\text { of quinones }\end{array}$ \\
\hline $\begin{array}{l}1653 \\
1676\end{array}$ & 1678 & $\begin{array}{l}\mathrm{C}=\mathrm{O} \text { stretch of } \\
\text { quinones }\end{array}$ \\
\hline
\end{tabular}

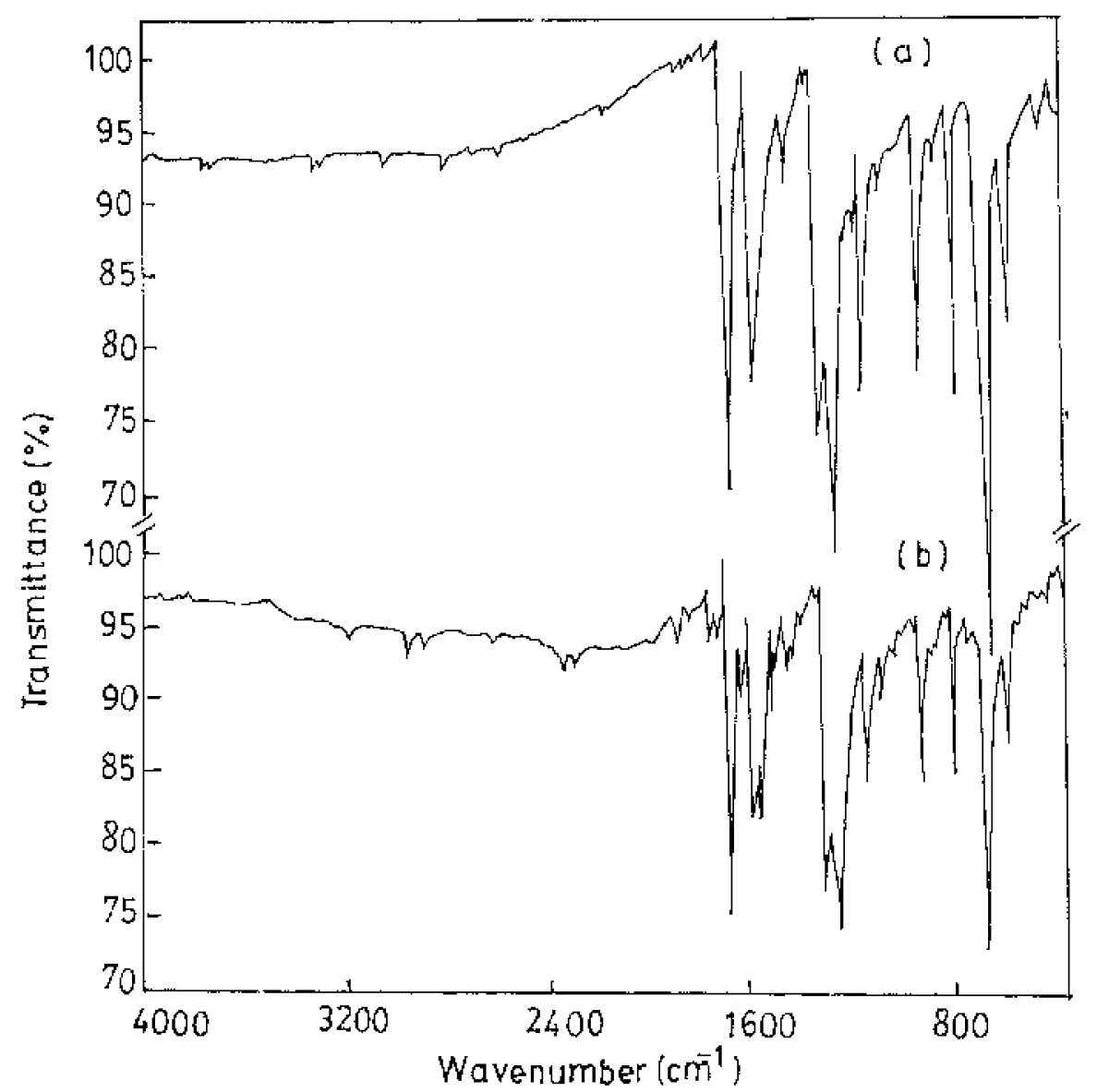

Figure 4. Infrared spectruth of anthraquinone needles grown (a) in aceane solutien incorponted over acctone mixed gel and (b) in acetone-water solution. 


\section{Characterization}

\subsection{Optical and scaming electron microscopy}

Optical micrographs of the single wystats of anthraquinone were taken using 'LEITZ ORTHLUX II POL BK' petrological microscope. Figure IB shows a needle of anthraqui- none nucleated from anthracene crystal substrate. Hollow cavity of the anthraquinone is also seen in the crystal. Figure $1 \mathrm{C}$ gives the micrograph of certain needles of anthraquinone obtained under crossed nicol position. A single crystal of anthraquinone photographed in straight extinction position with nicol in $45^{\circ}$ for maximum illu-

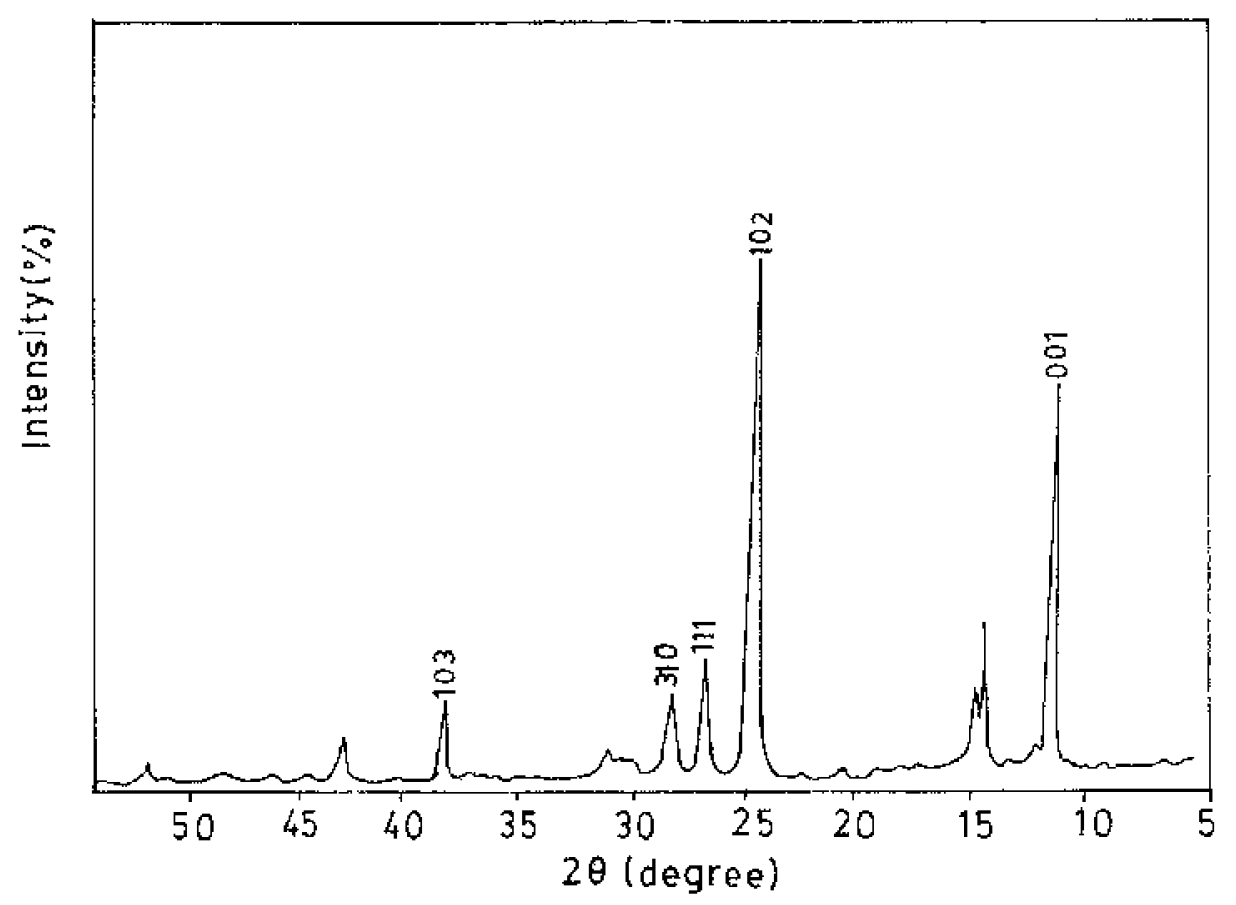

Figure 5. XRD patlern of anthrapuinono crystals.

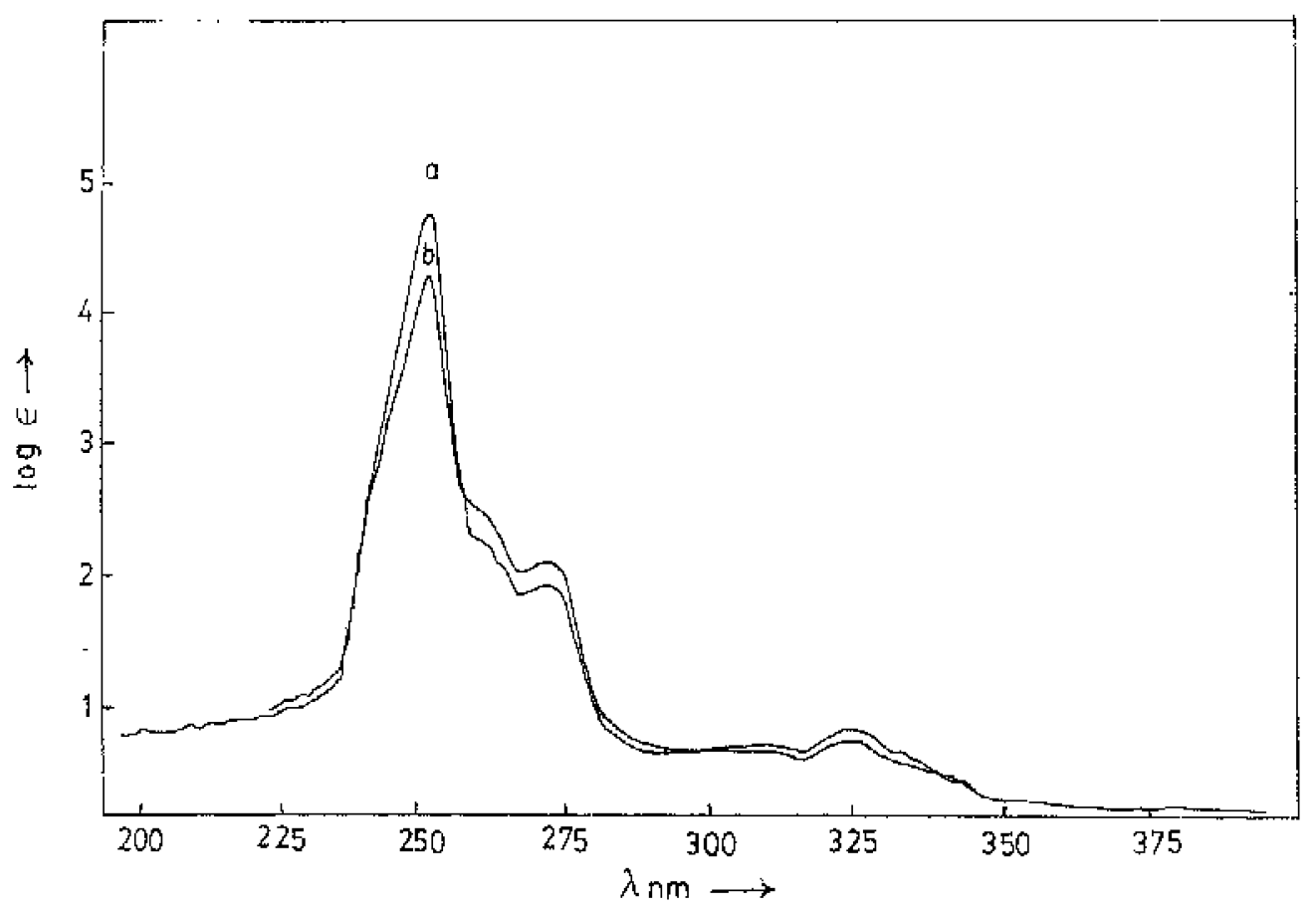

Figure 6. UV visible spectra of anthraquinone erystals (a) grown in acetone-water mixture and (b) grown by solution-gel technique. 
mination is given in figure 1D. Yellow needles of anthraquinone crystals grown in the supernalant solution kept over the gel is shown in figure $[A$. Figure $1 E$ shows the growth of large number of yellow needles in acetone-water solution of anthracene. The transparent tiny crystals at the bottom of the lest tube are anthracene. Figure IF gives the SEM picture of an anthraquinone needle.

\subsection{Infrared analysis}

The infrated spectra of the crystals were recorded in the range $4000-400 \mathrm{~cm}^{-1}$ by $\mathrm{KBr}$ pellet method. Preliminary analysis of the transparent crystalis formed on the top solution by IR spectroscopy has corfitrmed that the crystals ane anthracene. The IR spectrum of yellow needles grown in acetone solution and those grown in acetone-water mixture are given in figures $4 \mathrm{~A}$ and $\mathrm{B}$, respectively. The vibrational frequencies and their assignments are given in table 2 . The intense bands at 1676 and $1653 \mathrm{~cm}^{-1}$ can be assigned to the carbonyl grouping not present in anthracenc but seen in the case of anthraquinone (Singh and Singh 1968). The intense band at $694 \mathrm{~cm}^{-1}$ is identical to the ring breathing frequency reported for anthraguinone (Singh 1991).

\subsection{X-ray diffractim analysis}

The XRD scan of the crystals with $\mathrm{CuK}_{\mathrm{r}}$ radiation in the 20 range $0-50^{\circ}$ is shown in figure 5 . The calculated ' $d$ ' values $(0.360,0.762$ and $0.314 \mathrm{~nm})$ are found to be in close agreement with the ASTM ' $d$ ' values $(0.352$, 0.769 and $0.314 \mathrm{~mm}$ ) of anthracitinone.

\subsection{Ultravislet and risible spectroscopy}

UV-visible spectra of the anthraquinone crystals grown in this study were recotded using a SHMADZU UV$2100 \mathrm{~S}$, UV-visible recording spectrometer. The UVspectrum of the enthraquinone crystals dissolved in chlaroform is displayed in figure 6. Very strong band at $253 \mathrm{~nm}$ and the medium intense band at $273 \mathrm{~nm}$ are in agreement with reported values (Morton and Earlam 1941).

\section{Conclusion}

Formation of anthraquinone crystals was observed during the growth studies of anthracene. For all the $\mathrm{pH}$ valucs (5-7.5) tried, crystals of anthracuinone were obtained with varying nucleation time and quality. Better crystals of anthraquinone were obtained in $0.5 \%(w / v)$ solution of anthracene kept over acetone-mixed ge]s of pH 5 , 5.5 and 6 . Growth of needles into the gel medium wats observed for $\mathrm{pH} 5.5$. At higher concentration $(1 \% \mathrm{w} / \mathrm{v})$, nucleation and growth of anthracene occurred hindering photoreactive conversion to anthraquinone. Acetone mixed gel was found to be a better medium in aiding the growth of anthrajuinone rather than the pure gel. Solution studies have revealed that acetone-waler mixture can also be used as a solvent for growing anthraguinone crystals by photo reaction.

\section{References}

Chung R. H 1978 Encyl Chemn. Technol. 2700

Corcy E J and Taylor W C 1964 . I. Chem. Soc. 863881

Das C K and Nikhilendu S 1982 J. Cherr. Technol. Biptect. 32643

Grorev G. Anaslusov A, Peshev K and Elenkov D 1976 Intr. Khin. 9681

Ivan M R and William A w 1949 d. Chem. Soc, 30602

Louis F F and Mary F 1960 Organic chenistry (New York: Reinhold Publishing Comparty) p. 760

Maljk M and Dohnal I 1990 Czech Cs 241

Margare C E, Donalk A J and Brain S D 1986 f. Cryit. Gowir 76645

Mizoguchi $\mathrm{A}$ and Verishi $\mathrm{N} 1991 \mathrm{Jm}$. Kokai Tokyo Koho 5 Morton R A and Earlan W T 1941 J. Chem Soc. Pont I I59 Nohotul S at al 1969 d. Chem. Soc. Jap. 421377

Owens H W 1958 Can. J. Chem. 36949

Pielichiouski J, Gurlau P and Polaczck I 1992 Fridges Kohle Togutisber 155

Rajendta Bahu K, Deepa M, Nair C M K and Vaidyan V K 1998 Cryst. Res. Technol. (in pressy

Singh S N 1991 thdion J. Pare \& Appl. Fhys. 28211

Singh S N and Singh R S 1968 Spectrochin Acta A\&B24 1591 YaO O D 1962 UKR Fiz. Zh. 7315 